\title{
Prevalence of Unrecognized Depression and Associated Factors Among Newly Diagnosed People Living with HIV/AIDS in West Shoa Zone, Ethiopia 2019, Cross-Sectional Study
}

Takele Kejela Tiki ( $\nabla$ takesibirat14@gmail.com )

Ambo University college of medicine and health science

Teferra Likassa Tusa

Ambo University College of Medicine and Public Health

Esayas Tadesse

Ambo University College of Medicine and Public Health

Mulugeta Gobena

Ambo University College of Medicine and Public Health

Primary research

Keywords: Depression, HIV/AIDS Perceived stress, Ethiopia, Prevalence, west shoa zone, Central Ethiopia

Posted Date: September 8th, 2020

DOl: https://doi.org/10.21203/rs.3.rs-71562/v1

License: (c) (i) This work is licensed under a Creative Commons Attribution 4.0 International License.

Read Full License 


\section{Abstract}

Background: Clinical depression has been associated with various chronic disease conditions. The chronic course of HIV, fostered by the use of antiretroviral therapy in infected patients, puts them at risk of developing clinical depression which unfortunately, is often undiagnosed and therefore untreated. This study aimed to assess Prevalence of unrecognized depression and associated factors among newly diagnosed people living with HIV/AIDS in west shoa zone, oromia regional state, central Ethiopia.

Method: Institutional-based cross-sectional study was implemented in 2019. A total of 429 newly diagnosed HIV-positive patients who had regular visit at selected public health facilities in west shoa zone, oromia regional state, central Ethiopia were included in the study. Systematic random sampling technique was used to recruit study participants. Patient Health Questionnaire item nine (PHQ-9) was used to assess depressive symptoms. In addition to this, HIV perceived stress scale was used to assess HIV-related perceived stress.

Result: A total of 429 study participants were included in the study, giving a response rate of $100 \%$. The mean age of the respondents was 37 years (SD \pm 10.04 ). This study revealed that $47.3 \%$ of HIV-positive patients had depression. Patients who had opportunity infection [AOR $=2.15,(95 \% \mathrm{Cl} 1.41,3.29)$ ], HIVrelated perceived stress $[\mathrm{AOR}=2.23,(95 \% \mathrm{Cl} 1.44,3.46)]$ and $\mathrm{CD} 4$ cell count $<200[\mathrm{AOR}=1.94,(95 \% \mathrm{Cl}$ $1.25,3.02)]$ were more likely to have depression as compared to individuals who had no opportunity infection, no perceived HIV stress and CD4 cell count $>200$, respectively.

Conclusion and recommendation: Having HIV-related perceived stress and opportunity infection of participant had statistically significant association with undiagnosed depressive. Training of health workers in ART clinics and availing manuals on assessing mental health issues is useful to screen and treat depression among HIV patients.

\section{Background}

Depression also known as major depressive disorder or clinical depression is a common mental health disorder that results in persistent sadness and loss of interest in activities previously enjoyed, for a period of at least 2 weeks [1]. It is commonly present as co morbidity in many chronic illnesses adding to the overall burden of disease [2]. One of such chronic illnesses is disease caused by infection with the human immunodeficiency virus (HIV) which has become a global pandemic with close to 36.9 million people living with the disease worldwide by the end of 2017, and 1 million deaths from the disease in the same year [3].

Depression is one of the most common mental disorders people with HIV/AIDS experience and negatively affects adherence to and outcomes of antiretroviral treatment (ART) [4-5]. Throughout the course of HIV infection, patients may experience depressive symptoms due to deteriorated health status, difficulty functioning, ART side effects, apathy, perceived stress stigma, and discrimination [6-7]. 
Studies conducted in different countries on prevalence of depression among HIV patients showed $25.6 \%$ in united state US [8], 42.3\% in Brazil [9], 40.9\% in china [10], 12\% in Malawi [11], 31\% in Nigeria [12], 33\% in eastern Nigeria [13], 58.75\% Delhi (India) [14], 26.7\% in Cameroon[15], 63\% in Cameroon [16] 63.1\% in Khartoum Sudan[17], 48.6\% in Hawassa, Ethiopia[18], 45.8\% in Gurage zone, Ethiopia[19],37.5\% in Addis Ababa, Ethiopia [20], 45.8\% in Harar, Ethiopia [21],41.7\% in Gimbi general hospital [22].

In different studies so far, sex, having co morbid TB illness, perceived HIV stigma, poor social support, HIV stage III, and poor medication adherence and CD4 cell count $(<200)$ were found significantly associated with depression. But site specific evidence is needed to identify factors associated with depression among adult patients with HIV/AIDS on ART [18, 23, 24, 25 and 26]. More over it is crucial to identify patients with undiagnosed depression for proper management of the disease. Thus, this research was aimed at providing data on the prevalence and factors associated with undiagnosed depression among newly diagnosed people living with HIV/AIDS.

\section{Method}

\section{Study design and setting}

An institutional-based cross-sectional study was employed. The study was conducted in the West Shoa zone, Oromia regional state, Ethiopia. In west Shoa zone there are eight public hospitals and ninety one health center. From those all hospital and twenty four health center have ART clinic. From this public health there are around 12272 ARV patients on follow up. The assessment was conducted from February 1, to April 30, 2020.

\section{Sample size estimation and recruitment of participants}

Single population proportion formula was used to calculate the sample size using the magnitude of depression in pregnant mothers in Ethiopia, 37.5\% [20], with a 95\% confidence interval, 5\% of margin error and with the calculated design effect of 2.5. A multi-stage sampling technique was used to select the study participants. Initially, three hospitals and ten health centers was selected by simple random sampling from a total of eight hospital and 24 health centers in West shoa zone which have ART clinic. Then three hospitals and ten health centers was selected proportionally by lottery method. Then total sample size was allocated proportionally to each selected public health institutions based on the number of target population. A total of 429 newly diagnosed PLWHIV on follow up at least for six month were recruited for the study. Those with hearing or cognitive impairment to the extent of impairing capacity to communicate adequately and unable to give informed consent to take part in the study were excluded from the study.

\section{Data collection instrument and data collectors}

Data were collected by trained data collectors. The presence of antenatal depression was assessed by the Patient Health Questionnaire item nine (PHQ-9). The prevalence of depressive symptoms, defined by 
PHQ-9 scale, this study a positive depression screen was defined as a PHQ-9 score greater than 9, among newly-diagnosed HIV-infected subjects during initial assessment [30]. We have used tools consisted of structured and standardized locally translated language psychosocial assessment instruments, most of

which have previously been used among persons living with HIV (PLWHIV) in Ethiopia by this study group [29].

\section{Data analysis}

The Statistical Package for Social Science (SPSS) version 21.0 was used for data analysis. Newly diagnosed PLWHIV on follow up socio-demographic, economic and clinical related characteristics were described using the statistics of frequency and percentage distributions. Further, bivariate logistic regression analysis was conducted to identify correlates of HIV/ AIDS depression. Variables with a pvalue $<0.25$ during bivariate analysis were entered into a multivariate logistic regression analysis to identify potential confounders. Then, adjusted OR was calculated using multivariate logistic regression analysis and the level of significance of association was determined. Significance level was declared at < 0.05 .

\section{Results}

\section{Socio- demographic characteristics of respondents}

A total of 429 PLWHIV were included in the study yielding a response rate of $100 \%$. The mean age $( \pm$ SD) of the PLWHIV was $37.68 \pm 10.04$ years, with ages ranging between 19 and 65 years. Out of 429 PLWHIV, $356(83 \%)$ were from the Oromo ethnic group, 183(42.7\%) had primary school education and249 (58\%) were married (Table 1).

\section{Clinical related characteristics}

Regarding the clinical related characteristics 179 (41.7\%) of the PLWHIV had Past opportunistic infection, 173 (40.3\%) of PLWHIV their spouse had history of Chronic illness , 286(66.7\%) their Cd4 cell counts was greater 200 and 235 (54.8\%) had a history of HIV/AIDS related perceived stress (Table 2).

\section{Prevalence and factors associated with newly diagnosed HIV/AIDS depression}

The prevalence of undiagnosed depression among newly diagnosed HIV/AIDS patients was $47.3 \%$. The following variables were not significantly associated with newly diagnosed HIV/AIDS depression in the bivariate analysis: age, ethnic group, religion, marital status, educational status, occupational status, monthly family income, religion supportive care, TB test, TB treatment history and HIV sero status disclosure of respondents. However, residence, weight, health condition of spouse, CD4 cell counts and HIV related perceived stress were statistically associated with depression in the bivariate analysis. In the multivariable analysis, the study participants who had opportunity infection [AOR $=2.15(1.41,3.29)$ ] were 2.15times more likely to develop depression as compared to had no opportunity infection. 
Patients who had perceived HIV/AIDS stress [AOR $=2.23,95 \% \mathrm{Cl}(1.33,3.46)]$ were 2.2 times more likely to be depressed as compared to those who had not. The probability of occurring depression was 2 times higher among participant who were CD $4 \leq 200$ cell counts when compared to CD $4>200$ cell counts $[\mathrm{AOR}=1.94,95 \% \mathrm{Cl}(1.25,3.02)]$ (table 3$)$.

\section{Discussion}

In this study, the prevalence of undiagnosed depression among adult newly diagnosed HIV/AIDS patients on ART was $47.3 \%$, which is in line with a study conducted in Hawassa University Comprehensive specialized hospital Ethiopia (48.6\%) [18], 45.8\% in Harar [21],in Alert Hospital Addis Ababa, Ethiopia $41.2 \%$ [20], in Gimbi general hospital $41.7 \%$ [22]. But it is relatively low as compared to $63.1 \%$ in Khartoum Sudan [17], in Cameroon 63\% [16] and Delhi (India) 58.75\% [14], on the other hand it is relatively higher than in Cameroon 26.7\%, in Nigeria 23.4\% [13] in China 40.9\% [10], in Brazil 42.3\% [9], in gurage zone Ethiopia $37.5 \%$ [19]. The difference might be related to study design, data collection tool, sample size and study participant's variation.

Clients who had perceived HIV/AIDS stress were 2.2 times more likely to have depressive symptom when compared to clients who had had perceived HIV/AIDS stress [AOR $=2.23,95 \% \mathrm{Cl}(1.33,3.46)]$. The justification might be due to the fact that those who isolated themselves from others lead to worsening the depression.

In this study, we found a positive correlation between HIV/AIDS related perceived stress and depression. Su et al. found that perceived stress was associated with depression and perceived stress mediates the relationship between perceived discrimination and depression [27].

Furthermore, it can increase the psychological stress of patients and the risk of having depression. It was estimated that there are approximately about 550,000 MLWHA in China in 2011 [28]. Therefore, perceived stress is a psychological burden that may be associated with the occurrence of depression, and the elimination of discrimination requires active interventions at different levels.

Individuals who had $\leq 200$ CD 4 cell count had significant association with undiagnosed depression. This was similar to the study conducted in Hawassa University Compressive Specialized hospital Ethiopia [18], and Nigeria [25]. This might be due to severe immune depression and HIV illness is underlining causes of depression

The finding of this study also showed that those who had history of opportunistic infection were more likely to develop depression. This might be due to the fact that opportunistic infection may lead to dissatisfaction with one's physical appearance, which might be a reason for the occurrence of depression. This finding is consistent with study done in Gimbi general hospital [22].

\section{Conclusion}


Undiagnosed depression was high (47.3\%) among the current study population. Perceived HIV-related stress, had opportunity infection and CD4 count $(<200)$ had significant association with depression. Hence, depression is highly prevalent among newly diagnosed HIV-positive patients, still under diagnosed and undertreated but it needs further research. Therefore, Ministry of Health should give more emphasis to those clients with depression. Further research on effect of depression should be conducted to strengthen and broaden the current findings.

\section{Declarations}

\section{Acknowledgements}

The authors express their deep appreciation to the college of medicine and health science of ethics committee of the Ambo University, as well as the West Shoa zone health bureau ethical committee for allowing this study to be conducted in the selected public health facilities. The authors would also like to acknowledge all the data collectors and supervisors as well as the study participants for their participation.

\section{Authors' contributions}

TT conceived the study and was involved in the study design, reviewed the article, analysis, report writing and drafted the manuscript. TL, ET and MG were involved in the study design and analysis. All authors read and approved the final manuscript

\section{Funding}

This study was funded by the Ambo University, Research and community service core process. The funder had no role in study design, data collection, analysis and decision to publish.

\section{Availability of data and materials}

The dataset pertaining to this study will be shared upon reasonable request.

\section{Ethics approval and consent to participate}

Before data collection, ethical clearance letter was obtained from the ethical clearance committee of Ambo University, college of medicine and health sciences. Formal letter of permission was obtained from the selected public health facilities. Finally, oral and written informed consent was requested from the study participant after clearly explaining the objectives of the study. The participants were also informed that they may withdraw themselves at any stage of the data collection period.

\section{Consent for publication}

Not applicable. 


\section{Competing interest}

The authors declare that they have no competing interests

\section{References}

1. WHO 2017. Depression. Available from: http://www.who.int/mental_health/management/depression/en / Accessed on May 18, 2018.

2. Ferrari AJ, Charlson FJ, Norman RE, Patten SB, Freedman G, Murray CJ et al. Burden of depressive disorders by country, sex, age and year: findings from the Global Burden of Disease Study 2010. PLoS Med. 2013; 10(11): e1001547.

3. WHO 2017. Global Health Observatory data. Available from: http://www.who.int/gho/hiv/en/ . Accessed on May 18, 2018.

4. WHO. Mental health and development: targeting people with mental health condition as a vulnerable group. Geneva: World Health Organization; 2010.

5. Eller, L.S.; Bunch, E.H.; Wantland, D.J.; et al. Prevalence, correlates, and self-management of hivrelated depressive symptoms. AIDS Care 2010, 22, 1159-1170.

6. Pappin, M.; Wouters, E.; Booysen, F.L. Anxiety and depression amongst patients enrolled in a public sector antiretroviral treatment programme in south africa: A cross-sectional study. BMC Public Health 2012, 12, 244,

7. Bhatia, M.S.; Munjal, S. Prevalence of depression in people living with hiv/aids undergoing art and factors associated with it. J. Clin. Diagn. Res. 2014, 8, WC01-WC04.

8. Do AN, Rosenberg ES, Sullivan PS, et al. Excess burden of depression among HIV-infected persons receiving medical care in the United States: Data from the medical monitoring project and the behavioral risk factor surveillance system. PLoS ONE. 2014; 9(3): e92842.

9. Renata K.,Elizabete S., Carolina de C. etal . Prevalence and factors associated with depressive symptoms in individuals living with HIV/AIDS, 40, No. 2, marzo-abril 2017.

10. Liu $\mathrm{H}$, et al. Identifying factors associated with depression among men living with HIV/AIDS and undergoing antiretroviral therapy: a cross sectional study in Heilongjiang, China. Health Quality of Life Outcomes. 2018;16:190.

11. Jullita K., Kathryn E., Mina C.etal Prevalence and correlates of probable depression diagnosis and suicidal ideation among patients receiving HIV care in Lilongwe, Malawi Malawi Medical Journal (4);236-242 December 2018.

12. Onyebuchi-Iwudibia O, Brown Amy. HIV and depression in Eastern Nigeria: The role of HIV-related stigma. AIDS Care. 2014; 26(5): 653-7.

13. Halima M., Patricia A., Raphael O.etal . Prevalence of Depression and Associated Factors in HIVPositive Adults Attending an Antiretroviral Clinic in Jos, Nigeria. Journal of Family Medicine and Health Care, 2018 4(4): 26-32. 
14. Bhatia MS, Munjal S. Prevalence of depression in people living with HIV/ AIDS undergoing ART and factors associated with it. J Clin Diagn Res Jcdr. 2014;8:WC01.

15. L'akoa RM, Noubiap JJ, Fang Y, Ntone FE, Kuaban C. Prevalence and correlates of depressive symptoms in HIV-positive patients: a cross-sectional study among newly diagnosed patients in Yaoundé, Cameroon. BMC psychiatry 2013;13:228.

16. L'akoa RM, Noubiap JJN, Fang (2013). Prevalence and correlates of depressive symptoms in HIVpositive patients: a cross-sectional study among newly diagnosed patients in Yaounde ', Cameroon. BMC Psychiatry; 13:228.

17. A.Elbadawi andH. Mirghani,“Depressionamong HIV/AIDS Sudanese patients: a cross-sectional analytic study," The Pan AfricanMedicalJournal,vol.26,p.43,2017.

18. Bereket D., Epherem G., Mahlet Z.etal . Prevalence and associated factors of depression among patients with HIV/AIDS in Hawassa, Ethiopia, (2018) 17:45.

19. Haile W. ,Berhanu W. and Teshome H. etal . Prevalence and Associated Factors of Depression among HIV/AIDS Patients Attending Anti-Retroviral Therapy Clinics at Gurage Zone Selected Government Hospitals, Southwest, South nations, Nationalities and Peoples' Region, Ethiopia, 2018

20. TesfawG, Ayano G., Awoke T. etal. Prevalenceandcorrelates of depressionandanxietyamongpatientswithHIV on-follow up at Alert Hospital, Addis Ababa, Ethiopia, BMC Psychiatry, 368,2016.

21. Mohammed,M Mengistie,B Dessie,Y and Godana W. "Prevalence of depression and associated factors among HIV patients seeking treatments in ART clinics at harar town, Eastern Ethiopia," AIDS \& Clinical Research, pp. 2155-6113, 2015.

22. Muktar Abadiga. Depression and its associated factors among HIV/AIDS patients attending ART clinics at Gimbi General Hospital, West Ethiopia, BMC Res Notes https://doi.org/10.1186/s13104019-4553-0 (2019) 12:527

23. G. Dejenu and S. Zewdu, "Prevalence and Associated Factors of Depression among HIV Infected Patients in Debre Markos Town Northwest Ethiopia," International JournalofEmergency MentalHealthandHumanResilience,vol.17,no.1522-4821,pp. 714-716,2015.

24. D. Asmare Eshetu and S. Meseret, "Prevalence of Depression and Associated Factors among HIV/ AIDS Patients Attending ART Clinic at Debrebirhan Referral Hospital, North Showa, AmharaRegion,Ethiopia,"JournalofClinicalPsychiatry,vol.1, no.1,2015.

25. Freeman M, Nkomo N, Kafaar Z, Kelly K. Factors associated with prevalence of mental disorder in people living with HIV/AIDS in South Africa. AIDS Care. 2007;19:1201-9.

26. Omonefe Seb-Akahomen, Ambrose Lawani, Bawo Jame Mood and anxiety disorders adversely influence medication adherence to antiretroviral therapy among people living with HIV/AIDS in Nigeria Article in HIV and AIDS Review · June 2018)

27. Su X, Lau JTF, Mak WWS, Choi KC, Chen L, Song J, Zhang Y, Zhao G, Feng T, Chen X. Prevalence and associated factors of depression among people living with HIV in two cities in China. J Affect Disord. 2013;149:108-15.) 
28. Psychological stress 2011: UNAIDS: China Epidemic \& Response. http://www.unaids.org.cn/en/index/asp? id=197\& class=2\&classname=China+Epidemic $+\% 26+$ Response (2011). Accessed 26 Jul 2018.)

29. World Health Organization,(2017). WHO case definitions of HIV for surveillance and revised clinical staging and immunological classification of HIV-related disease in adults and children, http://www.who.int/hiv/pub/guidelines/HIVstaging150307.

30. Bizu Gelayea, ljala Wilsona, Hanna Y. Berhane etal. Diagnostic Validity of the Patient Health Questionnaire-2 (PHQ-2) among Ethiopian Adults, Compr Psychiatry. 2016 October ; 70: 216-221. doi:10.1016/j.comppsych.2016.07.011.

\section{Tables}


Table 1

Socio-demographic characteristics of newly diagnosed PLWHIV on ART $(n=429)$ on follow up at health facilities in West Shoa zone, Oromia Region Ethiopia, 2020

\begin{tabular}{|c|c|c|}
\hline Variables & frequency & Percentage \\
\hline \multicolumn{3}{|l|}{ Age of respondents } \\
\hline Less than 30 & 125 & 29.1 \\
\hline Greater or equal 30 & 304 & 70.9 \\
\hline Total & 429 & 100.0 \\
\hline \multicolumn{3}{|l|}{ Sex of respondents } \\
\hline Male & 235 & 54.8 \\
\hline Female & 194 & 45.2 \\
\hline Total & 429 & 100.0 \\
\hline \multicolumn{3}{|c|}{ Ethnicity of respondents } \\
\hline Oromo & 356 & 83.0 \\
\hline Amhara & 49 & 11.4 \\
\hline Others & 24 & 5.6 \\
\hline \multicolumn{3}{|c|}{ Religion of respondents } \\
\hline Orthodox Christian & 211 & 49.2 \\
\hline Protestant Christian & 153 & 35.7 \\
\hline Muslim & 35 & 8.2 \\
\hline Waqeffataa & 30 & 7.0 \\
\hline Total & 429 & 100.0 \\
\hline \multicolumn{3}{|c|}{ Educational status of respondents } \\
\hline No formal education & 124 & 28.9 \\
\hline Primary school & 183 & 42.7 \\
\hline Secondary school & 66 & 15.4 \\
\hline Higher educated & 56 & 13.1 \\
\hline Total & 429 & 100.0 \\
\hline \multicolumn{3}{|c|}{ Occupational status of respondents } \\
\hline Gov't employee & 59 & 13.8 \\
\hline
\end{tabular}




\begin{tabular}{|c|c|c|}
\hline Variables & frequency & Percentage \\
\hline Merchant & 104 & 24.2 \\
\hline farmer & 99 & 23.1 \\
\hline student & 50 & 11.7 \\
\hline Daily worker & 48 & 11.2 \\
\hline others & 69 & 16.1 \\
\hline total & 429 & 100.0 \\
\hline \multicolumn{3}{|l|}{ Marital status of respondents } \\
\hline Single & 66 & 15.4 \\
\hline Married & 249 & 58 \\
\hline Divorced & 52 & 12.1 \\
\hline widowed & 24 & 5.6 \\
\hline Separated & 38 & 8.9 \\
\hline Total & 429 & 100.0 \\
\hline \multicolumn{3}{|l|}{ Dependent child at home } \\
\hline yes & 327 & 76.2 \\
\hline No & 102 & 23.8 \\
\hline Total & 429 & 100.0 \\
\hline \multicolumn{3}{|c|}{ Family monthly income of respondents } \\
\hline Less or equal 500 & 134 & 31.2 \\
\hline 501 up to 900 & 81 & 18.9 \\
\hline 901 up to 2000 & 173 & 33.3 \\
\hline Equal or greater than 2000 & 71 & 16.6 \\
\hline Total & 429 & 100.0 \\
\hline \multicolumn{3}{|l|}{ Residence of respondents } \\
\hline Urban & 292 & 68.1 \\
\hline Rural & 137 & 31.9 \\
\hline Total & 429 & 100.0 \\
\hline
\end{tabular}


Table 2

clinical related factors of newly diagnosed PLWHIV on ART follow up $(n=$ 429) on follow up at health facilities in West Shoa zone, Oromia Region

Ethiopia, 2020

\begin{tabular}{|c|c|c|}
\hline Variables & Frequency & Percentage \\
\hline \multicolumn{3}{|l|}{ Past opportunistic infection } \\
\hline Yes & 179 & 41.7 \\
\hline No & 250 & 58.3 \\
\hline \multicolumn{3}{|l|}{ History past TB test } \\
\hline Yes & 368 & 85.8 \\
\hline No & 61 & 14.2 \\
\hline Total & 429 & 100.0 \\
\hline \multicolumn{3}{|l|}{ Past TB treatment history } \\
\hline Yes & 97 & 22.6 \\
\hline No & 332 & 77.4 \\
\hline \multicolumn{3}{|l|}{ CD4 cell counts } \\
\hline CD4 > 200 & 286 & 66.7 \\
\hline CD4 $\leq 200$ & 143 & 33.3 \\
\hline Weight of respondents during data collection & 429 & 100.0 \\
\hline Less than $50 \mathrm{~kg}$ & 176 & 41.0 \\
\hline Greater than or equal $50 \mathrm{~kg}$ & 253 & 59.0 \\
\hline Total & 429 & 100.0 \\
\hline \multicolumn{3}{|l|}{ Having religion supportive care } \\
\hline Yes & 188 & 43.8 \\
\hline No & 241 & 56.2 \\
\hline Total & 429 & 100.0 \\
\hline \multicolumn{3}{|l|}{ HIV sero status disclosure } \\
\hline Yes & 347 & 80.9 \\
\hline No & 82 & 19.1 \\
\hline Total & 429 & 100 \\
\hline
\end{tabular}

Page 12/15 


\begin{tabular}{|lll|}
\hline Variables & Frequency & Percentage \\
\hline Health & 141 & 32.9 \\
\hline Chronic & 173 & 40.3 \\
\hline Dead & 68 & 15.9 \\
\hline Unknown & 47 & 11.0 \\
\hline Total & 429 & 100.0 \\
\hline HIV related Perceived stress scale & & \\
\hline Presence & 235 & 54.8 \\
\hline Absence & 194 & 45.2 \\
\hline
\end{tabular}


Table 3

factors associated with undiagnosed depression among PLWHIV on ART follow up $(n=429)$ on follow up at health facilities in West Shoa zone, Oromia Region Ethiopia, 2020

\begin{tabular}{|c|c|c|c|c|}
\hline \multirow[t]{2}{*}{ Variables } & \multicolumn{2}{|c|}{ Depression } & \multirow[t]{2}{*}{$\operatorname{COR}(95 \% \mathrm{Cl})$} & \multirow[t]{2}{*}{$\operatorname{AOR}(95 \% \mathrm{Cl})$} \\
\hline & presence & Absence & & \\
\hline \multicolumn{5}{|l|}{ Sex of respondents } \\
\hline Male & 95 & 140 & 1.00 & 1.00 \\
\hline Female & 108 & 86 & $1.85(1.23,2.72)$ & $1.48(0.98,2.23)$ \\
\hline \multicolumn{5}{|l|}{ Residence } \\
\hline Urban & 149 & 143 & $1.60(1.06,2.43)$ & $1.70(1.10,2.61)^{\star \star}$ \\
\hline Rural & 54 & 83 & 1.00 & 1.00 \\
\hline \multicolumn{5}{|l|}{ Past opportunistic infection } \\
\hline Yes & 98 & 81 & $1.67(1.14,2.46)$ & $2.15(1.41,3.29)^{\star *}$ \\
\hline No & 105 & 145 & 1.00 & 1.00 \\
\hline \multicolumn{5}{|c|}{$\begin{array}{l}\text { Weight of respondents during data } \\
\text { collection }\end{array}$} \\
\hline \multicolumn{5}{|l|}{ CD 4 cell count } \\
\hline CD $4>200$ & 119 & 167 & 1.00 & 1.00 \\
\hline$C D \leq 200$ & 84 & 59 & $1.99(1.33,3.00)$ & $1.94(1.25,3.02)^{\star *}$ \\
\hline Less than $50 \mathrm{~kg}$ & 94 & 82 & $1.51(1.03,2.23)$ & $1.11(0.72,1.70)$ \\
\hline Greater than or equal $50 \mathrm{~kg}$ & 109 & 144 & 1.00 & 1.00 \\
\hline \multicolumn{5}{|l|}{ Health condition of spouse } \\
\hline Health & 57 & 84 & 1.00 & 1.00 \\
\hline Chronic & 86 & 87 & $1.46(0.93,2.28)$ & $1.44(0.68,2.39)$ \\
\hline Dead & 40 & 28 & $2.11(1.17,3.79)$ & $1.69(0.91,3.14)$ \\
\hline Unknown & 20 & 27 & $1.09(0.56,2.13)$ & $1.16(0.57,2.37)$ \\
\hline \multicolumn{5}{|l|}{ Perceived stress } \\
\hline Presence & 75 & 119 & $1.90(1.29,2.79)$ & $\begin{array}{l}2.23(1.44 \\
3.46) * \star\end{array}$ \\
\hline Absence & 128 & 107 & 1.00 & 1.00 \\
\hline
\end{tabular}

Figures 


\section{Prevalence of undiagnosed depression among newly diagnosed people living with HIV/AIDS}

$\square 1 \square 2$
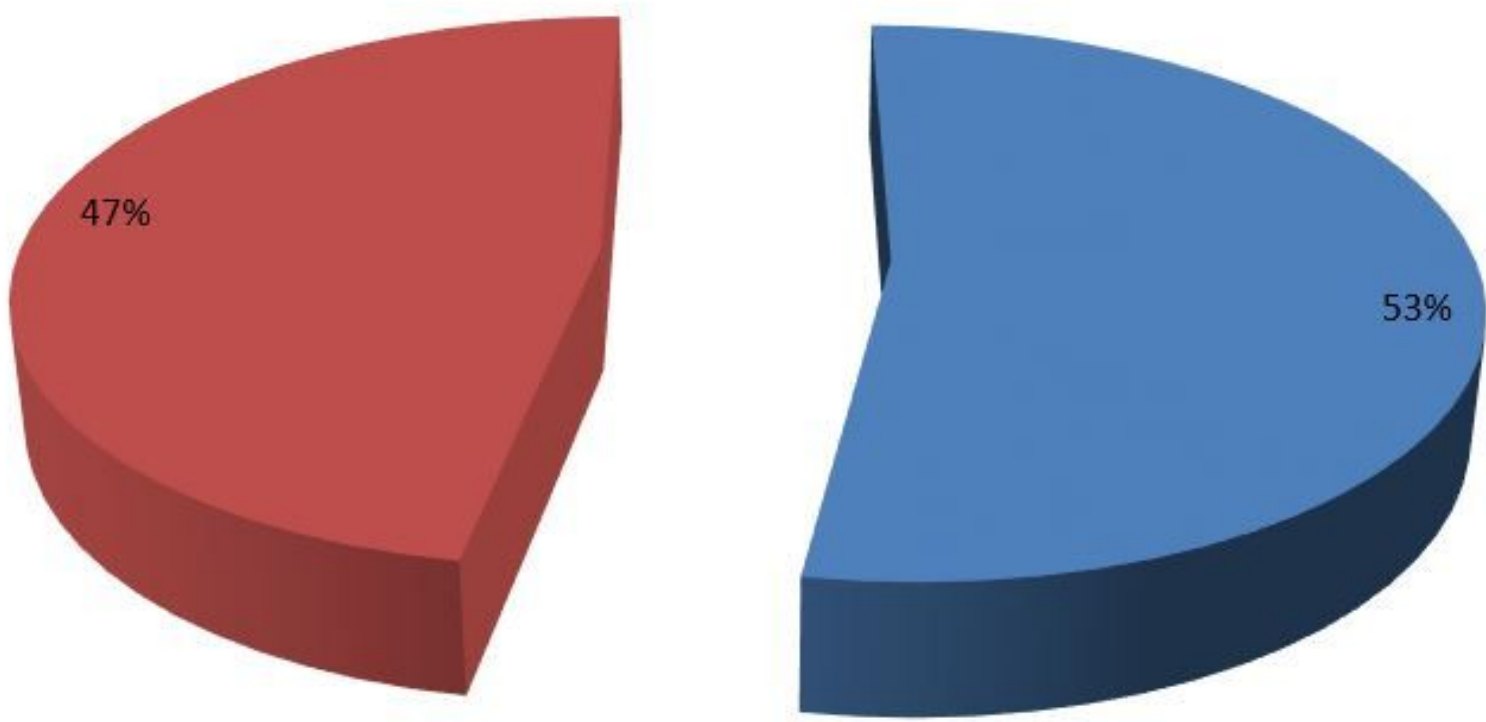

Figure 1

Prevalence of undiagnosed depression among newly diagnosed PLWHIV on follow up in west shoa zone health facilities, oromia regional state, Ethiopia 2020 